\title{
Preface: Remote sensing, modelling-based hazard and risk assessment, and management of agro-forested ecosystems
}

\author{
Jonathan Rizzi ${ }^{1}$, Ana M. Tarquis ${ }^{2}$, Anne Gobin ${ }^{3,4}$, Mikhail Semenov ${ }^{5}$, Wenwu Zhao ${ }^{6}$, and Paolo Tarolli ${ }^{7}$ \\ ${ }^{1}$ Department of Geomatics, Norwegian Institute of Bioeconomy Research (NIBIO), Ås, 1435, Norway \\ ${ }^{2}$ Centro de Estudios e Investigación para la Gestión de Riesgos Agrarios y Medioambientales (CEIGRAM), \\ Universidad Politécnica de Madrid (UPM), Madrid, Spain \\ ${ }^{3}$ Department of Earth and Environmental Sciences, Faculty of Bioscience Engineering, \\ Katholieke Universiteit Leuven, 3001 Heverlee, Belgium \\ ${ }^{4}$ Flemish Institute for Technological Research, $2400 \mathrm{Mol}$, Belgium \\ ${ }^{5}$ Rothamsted Research, Harpenden, Herts, AL5 2JQ, UK \\ ${ }^{6}$ State Key Laboratory of Earth Surface Processes and Resource Ecology, Faculty of Geographical Science, \\ Beijing Normal University, Beijing 100875, China \\ ${ }^{7}$ Department of Land, Environment, Agriculture and Forestry, University of Padova, 35020, Legnaro, Italy
}

Correspondence: Jonathan Rizzi (jonathan.rizzi@nibio.no)

Published: 23 December 2021

\section{Introduction}

Agricultural and forested landscapes cover large areas over many countries; they are a very important natural resource that needs to be managed sustainably for both the environment and the local communities. Food security, population growth, urbanization, and intensive agricultural development are some of the factors that generate increasing demands for water and land resources in the context of global change. Therefore, potential impacts deriving from a changing climate, from more frequent and intense extreme events, and from anthropogenic activities can pose serious threats to economic infrastructure and development in the coming decades and also severely undermine food, fodder, water, and energy security for a growing global population.

Significant recent changes in climate and in the hydrological cycle will impact land suitability for agricultural production and forest ecosystems. In particular, we can expect an increase, in some regions, in the frequency and intensity of extreme weather and weather-related events such as heat waves, floods, wind and snowstorms, droughts, etc. (IPCC, 2012; IPCC, 2021). Furthermore, anthropogenic activities can exacerbate consequences of an unbalanced environment, such as water quality degradation, groundwater depletion, land subsidence, erosion, and sedimentation (Delkash et al., 2018; Tarolli and Straffellini, 2020). Therefore, sustainable man- agement and exploitation of first-order agricultural resources and forested areas, e.g. available land with favourable climate, soil, and water, will become even more important in the lives and activities of people.

The 10 original papers included in this special issue address several of these aspects. In particular one review paper provides a general introduction to risk assessment for natural hazards, six papers focus on water- and weather-related hazards (four related to agriculture and two related to water quality at river basin scale), two papers address hazard assessment for the insurance sector, and one paper is related to challenges in agriculture-forest frontiers. The presented researches adopt different types of quantitative and qualitative modelling and spatial analysis and use remote sensing data, when relevant.

\section{Risk assessment for natural hazards}

The review paper by Nastos et al. (2021) analyses meteorological hazards and extremes (tornadoes, waterspouts, hailstorms, heat waves, droughts, floods, heavy convective precipitation, landslides, and wildfires) in Mediterranean ecosystems using a risk management framework, which is relevant to a better understanding of the different steps and possible applications. The described framework consists of 
four main steps: (i) risk identification, (ii) risk estimation, (iii) risk evaluation, and (iv) feedback analysis. The first step (i.e. risk identification) includes activities such as the development of a database containing information about previous events of the considered hazard and its effects. The second step (i.e. risk estimation) includes the analysis of the magnitude and/or frequency of hazards and the assessment of the economic costs, as well as the social consequences (also including cost-benefit analysis and community policy assessment). Through a series of case study descriptions, the authors of the paper show practical applications of the different steps of the proposed framework. Case studies are located around the Mediterranean basin region, with a special focus on the wider area of Greece in the eastern Mediterranean.

\section{Water-related hazards and weather modelling in agriculture}

Water-related hazards in agriculture are particularly important and are related to variations in water availability in the form of surpluses and shortages of water. Two papers of the special issue are focused on drought, which is a relevant topic for an increasing number of regions worldwide.

Spatial indicators for desertification in southeastern Vietnam have been identified by Hien et al. (2019). In their study they show that desertification can be driven by a number of different, heterogenous factors not limited to climate and water management but also related to soil, topography, geology, vegetation, human pressure, and land cover and land use. These factors have all a spatial component and can therefore be used as geo-information for developing spatial indicators. Based on these indicators, a framework was proposed for the detection of areas at risk of desertification and for the identification and quantification of the main contributing factors. In the case study of the Binh Thuan Province in southeastern Vietnam, the assessment is performed for a baseline scenario (i.e. 2010) and for a future scenario (i.e. 2050) by using climate change projections and an estimation of population change. Results show that the area at risk of desertification can double over a period of 40 years, from $14.4 \%$ in 2010 to $31.9 \%$ in 2050 . The proposed approach supports a sound risk assessment. By adopting a "what if" structure, the method allows the creation of multiple comparable scenarios for the considered region, supporting decision-making. Although the application of the described method might need to be adapted by identifying the most suitable indices for each specific application, the proposed approach for combining different indices into the environmentally sensitive area indicator (ESAI) can be translated to other regions.

Another index-based approach for drought is presented by Jiménez-Donaire et al. (2020). In this work, the proposed combined drought indicator (CDI) classifies the level of risk in four classes by integrating three main elements: (i) rainfall, using the Standardized Precipitation Index (SPI) for the evaluation of trends in rainfall; (ii) soil moisture, evaluated by using a bucket-type model that allows monitoring of soil moisture and calculation of anomalies; and (iii) vegetation dynamics and response to changes in soil moisture, by monitoring the Normalized Difference Vegetation Index (NDVI) from the MODIS Terra satellite. The proposed approach has been tested in several regions in southern Spain characterized by an irregular precipitation regime. The comparison of the observed crop damages reported from insurance companies with the classification resulting from the proposed approach shows good agreement. More specifically, the proposed CDI dynamics have been assessed for a 10-year period (from September 2003 to September 2013). During this period there have been two important drought events affecting five rainfed cereal-growing regions in southwestern Spain with around $70 \%$ to $95 \%$ of the crops damaged: 2004-2005 and 2011-2012. The values of the CDI show critical values during both drought event periods, demonstrating the potential of the CDI for the assessment of agricultural drought. The proposed approach based on the CDI can be successfully replicated also in other regions since it is based on indicators that can be calculated everywhere.

When dealing with natural hazards in agriculture it is particularly important to have good weather and climate models for estimating several relevant variables for hazard and risk characterization. Two papers of the special issue address modelling of weather-related information, particularly relevant for application in agriculture.

An analysis of different modelling approaches for chilling accumulation in fruit trees in Spain under climate change is presented by Rodríguez et al. (2019). The estimation of chilling temperatures is important to identify the passage from the period when a plant stops growing due to the low temperatures to the growth phase. The global temperature increase will affect the period when this passage occurs, anticipating the beginning of the growing season. This can be particularly relevant, e.g. in fruit plantation, to have correct management and optimize the production cycle. The study compares different approaches applied to several regional climate models under different future climate scenarios. Results obtained for the Spanish case highlighted the risk of compromising the growth for some species but at the same time showed the potential for growth of other species. This is due to a general reduction of chilling accumulation that is expected across peninsular Spain and the Balearic Islands. All simulations agree in the general trend, and the largest reduction is expected for the RCP8.5 scenario in the period 2071-2100. Some varieties of chilling-demanding species could experience problems already within the 2021-2050 period. This analysis is therefore relevant for planning plantations for the coming years, particularly in regions where changes in temperature may require the implementation of adaptation measures to prevent climate change impacts.

Moratiel et al. (2020) address the issue of the estimation of evapotranspiration, a variable that is fundamental in 
agriculture-related studies and often difficult to estimate. Its importance is in connection with the planning of several activities, e.g. irrigation, as well as potential risks related to water deficits. Modelling of evapotranspiration can be particularly difficult in areas where there are few weather stations and therefore meteorological information on wind speed, solar radiation, or air humidity is not available. There are several methods to estimate evapotranspiration from air temperature and in the presented case, located in Spain, two Hargreaves-Samani models, with and without calibration, and five Penman-Monteith temperature models were used, and results were compared. These models were run using daily temperature data from 49 stations located across the studied basin. Results show that models tested on an annual or seasonal basis provide different performance, with higher $R^{2}$ values when performed annually. When using seasons, $R^{2}$ values are lower in summer-winter and higher in springautumn. The Nash-Sutcliffe error values are high for models tested from an annual perspective but when calculated for season, spring, and summer are low. During the winter none of the models showed good performances (although not problematic since winter is the season where evapotranspiration is less relevant). The value of the mean absolute error is dependent on wind speeds, with larger error in areas characterized by higher wind speed. The spatio-temporal analysis of the performance of different evapotranspiration models is particularly important to identify the best model to use for more efficient water management. The proposed approach proved to be useful to provide relevant information for water management, which is particularly relevant in all semi-arid regions where water availability is crucial for agricultural crops and there is a lack of agro-meteorological data.

\section{Risk assessment to support insurance companies in the agricultural sector}

Insurance companies can provide useful information to evaluate results of risk assessment methods, as presented by Jiménez-Donaire et al. (2020). At the same time, they can provide a big advantage by using robust, precise, and accurate methods for estimating hazard and risks in agricultural areas. The review includes two studies that can be relevant for the insurance sector.

Martín-Sotoca et al. (2019) present a statistical analysis for a satellite-index-based insurance to define damaged pasture thresholds. As documented, in many countries satellite data and derived indices such as the NDVI are being used to evaluate damaged pasture and forage and support insurance companies. For insurance based on satellite data the retrieved indices are analysed through statistical methods to quantify the occurrence of damage. In this study, the Generalized Extreme Value (GEV) distribution of the NDVI (derived from MODIS data) throughout the year is compared to a normal distribution, which is commonly used. Results showed that for the considered Spanish case, the GEV distribution performed better. The results of the proposed study suggest that there should not be an a priori distribution (either GEV or normal) and the NDVI threshold used to define damages should not be defined by using averages and standard deviations (typical of normal distributions) but rather should adopt a percentile methodology.

When dealing with index-based insurance, it is not only important to identify thresholds allowing a quantification of the damages, but it is also important to quantify the basis risk, as shown by Valverde-Arias et al. (2020), who evaluate the use of remote sensing in an index-based insurance design for hedging economic impacts on rice cultivation. In this paper, a method is presented for a spatially based quantification of the basis risk and of the damages and economic impacts, which is fundamental for ascertaining and quantifying losses without the need of an in situ verification, thus reducing operative costs and making the use of insurance easier in several regions. In the presented study, considering the presence of drought or floods by using the NDVI (calculated using MODIS data), two threshold values were defined: the first one allows the presence of an impact on the considered crop (i.e. physiological threshold) to be identified, while the second one allows the presence of an impact on the gross margin (i.e. economic threshold) to be identified. The final aim of these indices and thresholds are to support insurance companies in setting up accurate insurance premiums and compensation. The results of the analysis performed for two agroecological homogeneous zones for rice in Ecuador showed that these areas are characterized by different risk profiles. Therefore, the calculation of premium based on the risk status and insured amount of each area lead to a fairer insurance premium for farmers and would help them receive the correct compensation for the losses. Although the paper presents a case related to rice cultivation in Ecuador, the method can be adapted to other types of cultivations and/or other regions where data are available for defining agro-ecological homogeneous zones, crop yield, and production cost.

\section{Risk assessment and management for rivers and forests}

Risk assessment methods can be applied to riverine environments, and river management activities can largely benefit from the use of such methods. Two papers included in the special issue used risk assessment methods to address different environmental issues.

Chen et al. (2019) have monitored the seasonal dynamics of soil salinization in the Yellow River delta of China using Landsat data. The authors aim at assessing seasonal dynamics of salinization to control salinity and reduce its consequent risks and impacts. The assessment is based on the use of satellite data (in this case from Landsat) to calculate improved vegetation indices which are used to support the 
modelling of the salinity content in the soil. Soil salinity content (and its spatial distribution) was estimated for each season by using different approaches, including methods such as (i) stepwise multiple linear regression, (ii) back propagation neural network, and (iii) support vector machine. The proposed paper considered the Kenli District in the Yellow River delta (China) as a case study and the obtained results can support the monitoring of the hazard to take preventative measures in the management of the river basin. Results, which are consistent with field sampling data, showed that soil salinity concentration has a gradually increasing trend from the southwest to northeast, and soil salinity accumulated in spring, decreased in summer, increased in autumn, and reached its peak at the end of winter.

River basins can also be affected by anthropogenic disturbances, and the main example is the pollution coming from human activities. This is a relevant issue in many areas worldwide, and Lee et al. (2019) present a framework to prioritize watersheds for diffuse pollution management in the Republic of Korea by applying multicriteria decision analysis using the Delphi method. The proposed risk-based approach uses multicriteria decision analysis methods to integrate complex and heterogenous information related to nonpoint source pollution. The selection of the criteria and subcriteria to use in the assessment of the vulnerability is done by using the Delphi technique, integrating expert judgement into the assessment process in a systematic and structured way. The sub-criteria used in the evaluation received either quantitative or qualitative scores. The presented case study includes all non-point pollution sources present in the continental area of the Republic of Korea and includes the prioritization and the spatially based assessment of the vulnerability of the studied catchments. Results showed that the Nakdong River basin, which is part of the Nakdong River watershed, is the most vulnerable. In general, the more vulnerable watersheds that require preferential management are those where there is a large number of livestock and much fertilizer is used in a basin, leading also to high suspended soil concentration.

Blanco-Gutiérrez et al. (2020) examined the sustainability and development challenges in agricultural-forest frontiers of the Amazon Basin through the eyes of locals. Several forests around the world, with the Amazon being the most relevant example, are being degraded and deforested, mainly for agriculture expansion. Policies should consider and integrate socio-economic and environmental data, but this is particularly challenging for what concerns the consideration of local stakeholders. The study showed how participatory fuzzy cognitive mapping can be used to examine stakeholder perceptions towards the sustainable development of two regions in the Amazon Forest, using scenarios that also include climate change. Results showed that applied strategies boost positive regional changes. However, it also came out that current rural development programmes cannot continue, since having a focus only on conservation or on agricultural de- velopment policies would reduce resilience and allow future environmental degradation. In general, these types of activities can support the reduction of the risk of environmental degradation (in particular forests) and can improve the resilience to climate change of both the environment and local communities, thus reducing future risks.

\section{Conclusion}

Risk assessment for natural hazards is particularly important in agro-forested ecosystems, and its importance will be even higher in the future due to the increasing pressure on the environment from climate change and anthropogenic activities. This special issue collects several papers that present an overview of risk management frameworks (Nastos et al., 2021) and provide several examples of their application. Particularly important is the role of the presented methods for the insurance sectors (Martín-Sotoca et al., 2019; ValverdeArias et al., 2020): in a context of a changing climate, the use of insurance to protect the income of farmers will be crucial, especially in developing countries, which are particularly vulnerable to the changing climate and where the income from farming activities is the only source of income. Natural hazards, hydrology, and meteorology and climate sciences are often linked, and some of the papers included in the special issue confirm this close connection. It is important to be able to further improve the estimation of drought, as presented and discussed in the studies of Hien et al. (2019) and Jiménez-Donaire et al. (2020), as well as other variables, such as potential evapotranspiration (Moratiel et al., 2020) or chilling accumulation (Rodríguez et al., 2019), which play a key role in agricultural studies. Further, risk assessment has been proven to be a valid tool to evaluate different types of risk both in the riverine (Chen et al., 2019; Lee et al., 2019) and in the forest (Blanco-Gutiérrez et al., 2020) environments: although these environments are different, risk assessment methods play an important role in both. All the papers included in the special issue address specific issues and present local specific applications: however, the approaches presented and tested over different case studies can be applied to other cases and regions, directly or with specific adjustments. Open challenges remain and inspiration is provided for further research work in these topics.

Disclaimer. Publisher's note: Copernicus Publications remains neutral with regard to jurisdictional claims in published maps and institutional affiliations.

Special issue statement. This article is part of the special issue "Remote sensing, modelling-based hazard and risk assessment, and management of agro-forested ecosystems". It is not associated with a conference. 


\section{References}

Blanco-Gutiérrez, I., Manners, R., Varela-Ortega, C., Tarquis, A. M., Martorano, L. G., and Toledo, M.: Examining the sustainability and development challenge in agricultural-forest frontiers of the Amazon Basin through the eyes of locals, Nat. Hazards Earth Syst. Sci., 20, 797-813, https://doi.org/10.5194/nhess-20797-2020, 2020.

Chen, H., Zhao, G., Li, Y., Wang, D., and Ma, Y.: Monitoring the seasonal dynamics of soil salinization in the Yellow River delta of China using Landsat data, Nat. Hazards Earth Syst. Sci., 19, 1499-1508, https://doi.org/10.5194/nhess-19-1499-2019, 2019.

Delkash, M., Al-Faraj, F. A., and Scholz, M.: Impacts of anthropogenic land use changes on nutrient concentrations in surface waterbodies: a review, CLEAN - Soil, Air, Water, 46, 1800051, https://doi.org/10.1002/clen.201800051, 2018.

Hien, L. T. T., Gobin, A., and Huong, P. T. T.: Spatial indicators for desertification in southeast Vietnam, Nat. Hazards Earth Syst. Sci., 19, 2325-2337, https://doi.org/10.5194/nhess19-2325-2019, 2019.

IPCC: Climate Change 2021: The Physical Science Basis, in: Contribution of Working Group I to the Sixth Assessment Report of the Intergovernmental Panel on Climate Change, edited by: Masson-Delmotte, V., Zhai, P., Pirani, A., Connors, S. L., Péan, C., Berger, S., Caud, N., Chen, Y., Goldfarb, L., Gomis, M. I., Huang, M., Leitzell, K., Lonnoy, E., Matthews, J. B. R., Maycock, T. K., Waterfield, T., Yelekçi, O., Yu, R., and Zhou, B.: Cambridge University Press, in press, 2021.

Jiménez-Donaire, M. P., Tarquis, A., and Giráldez, J. V.: Evaluation of a combined drought indicator and its potential for agricultural drought prediction in southern Spain, Nat. Hazards Earth Syst. Sci., 20, 21-33, https://doi.org/10.5194/nhess-20-21-2020, 2020.

Lee, G., Jun, K. S., and Kang, M.: Framework to prioritize watersheds for diffuse pollution management in the Republic of Korea: application of multi-criteria analysis using the Delphi method, Nat. Hazards Earth Syst. Sci., 19, 2767-2779, https://doi.org/10.5194/nhess-19-2767-2019, 2019.
Martín-Sotoca, J. J., Saa-Requejo, A., Moratiel, R., Dalezios, N., Faraslis, I., and Tarquis, A. M.: Statistical analysis for satellite-index-based insurance to define damaged pasture thresholds, Nat. Hazards Earth Syst. Sci., 19, 1685-1702, https://doi.org/10.5194/nhess-19-1685-2019, 2019.

Moratiel, R., Bravo, R., Saa, A., Tarquis, A. M., and Almorox, J.: Estimation of evapotranspiration by the Food and Agricultural Organization of the United Nations (FAO) Penman-Monteith temperature (PMT) and Hargreaves-Samani (HS) models under temporal and spatial criteria - a case study in Duero basin (Spain), Nat. Hazards Earth Syst. Sci., 20, 859-875, https://doi.org/10.5194/nhess-20-859-2020, 2020.

Nastos, P. T., Dalezios, N. R., Faraslis, I. N., Mitrakopoulos, K., Blanta, A., Spiliotopoulos, M., Sakellariou, S., Sidiropoulos, P., and Tarquis, A. M.: Review article: Risk management framework of environmental hazards and extremes in Mediterranean ecosystems, Nat. Hazards Earth Syst. Sci., 21, 19351954, https://doi.org/10.5194/nhess-21-1935-2021, 2021.

Rodríguez, A., Pérez-López, D., Sánchez, E., Centeno, A., Gómara, I., Dosio, A., and Ruiz-Ramos, M.: Chilling accumulation in fruit trees in Spain under climate change, Nat. Hazards Earth Syst. Sci., 19, 1087-1103, https://doi.org/10.5194/nhess19-1087-2019, 2019.

Tarolli, P. and Straffelini, E.: Agriculture in hilly and mountainous landscapes: threats, monitoring and sustainable management, Geogr. Sustainabil., 1, 70-76, 2020.

Valverde-Arias, O. R., Esteve, P., Tarquis, A. M., and Garrido, A.: Remote sensing in an index-based insurance design for hedging economic impacts on rice cultivation, Nat. Hazards Earth Syst. Sci., 20, 345-362, https://doi.org/10.5194/nhess-20-3452020, 2020. 